\title{
Fatal neonatal nemaline myopathy: a case report
}

\author{
MITSUHIRO TSUUIHATA, ${ }^{*}$ CHIEKO SHIMOMURA,§ TOSHIRO YOSHIMURA, ${ }^{*}$ AKIRA \\ SATO,${ }^{*}$ TERUYUKI OGAWA,$\S$ YOSHIRO TSUJI, $\uparrow$ SHIGENOBU NAGATAKI, ${ }^{*}$ TAKESHI \\ MATSUO $\ddagger$
}

\author{
From The First Department of Internal Medicine, ${ }^{*}$ the Department of Pediatrics, $\dagger$ the Department of \\ Pathology, $\ddagger$ Nagasaki University School of Medicine, Nagasaki, the Department of Pediatrics, Ohita Medical \\ College, Ohita, § Japan
}

SUMMARY A fatal neonatal nemaline myopathy in a Japanese girl was described. The patient was hypotonic at birth and failed to establish effective respiration. Rod-like structures were observed within a variety of skeletal muscles, particularly in the diaphragm. This is the first case of fatal neonatal nemaline myopathy in which many satellite cells were observed.

There have been numerous reports of nemaline myopathy, usually with a mildly progressive or non-progressive course. Recently, however, there have been several reports of severe forms which may lead to death within the first year of life..$^{1-5}$ Here we report a patient with fatal neonatal nemaline myopathy whose muscles were studied by light and electron microscopy.

\section{Case report}

The patient's grandparents were first cousins, but both parents were normal on neurological examination. There was no family history of neuromuscular diseases. The patient, a girl, was born prematurely at 37 week's gestation. The pregnancy had been uneventful except for early rupture of the membranes during delivery. The birth weight was $3,220 \mathrm{~g}$. The infant was hypotonic at birth and failed to establish effective respiration. Because of dyspnoea, cyanosis and bradycardia, she was admitted to hospital. Only after initiation of mechanical respiration was her condition stabilised. She had a characteristic appearance, with a narrow face, high-arched palate, and syndactylia. The infant was hypotonic and areflexic, and had little spontaneous activity. There were no Moro or suck reflexes. Routine laboratory investigations were normal and included the following: complete blood count, urinalysis, liver function tests and electrolytes. The serum creatine kinase level and aldolase level were normal. The cerebrospinal fluid was normal. Electromyography was not per-

Address for reprint requests: Mitsuhiro Tsujihata, MD, the First Department of Internal Medicine, Nagasaki University School of Medicine, 7-1, Sakamoto-cho, Nagasaki, Japan.

Received 12 January 1983. Accepted 14 April 1983 formed. Death occurred at the age of 3 months and was attributed to wasting and pneumothorax.

Pathology muscle biopsy was performed of the right rectus femoris at the age of $\mathbf{3}$ months. With hematoxylin-eosin stain, there was marked variation in fibre size. No central nuclei, splitting, necrotic or regenerating fibres were identified. With the modified Gomori trichrome stain, numerous dark red granular deposits were identified in many fibres. With PTAH stain rod bodies were also clearly visible. As judged by myosin ATPase stain ( $\mathrm{pH} \mathrm{9.4,} \mathrm{4.7,}$ and $4 \cdot 3$ ), most of the small fibres were of histochemical type I and the large fibres of type II. No type grouping was observed. The rod bodies were observed in both type I and II fibres. The average muscle fibre diameter of type I and II fibres was $9.66 \pm 2.58 \mu \mathrm{m}$ and $16.34 \pm 3.21 \mu \mathrm{m}$, respectively. Several muscle specimens were obtained from the right rectus femoris, biceps brachii, intercostal muscle and diaphragm one hour after death. A sample of each skeletal muscle examined by light microscopy showed severe atrophy of muscle fibres except in the diaphragm. Numerous rods were observed in the majority of fibres in the diaphragm, but a small number of rods were observed in the other muscles. Ultrastructural studies of the biopsied rectus femoris revealed numerous rods in the fibres. It was, however, very difficult to demonstrate the lattice structures in the rods. The largest rod in the diaphragm was about 2.6 $\mu \mathrm{m}$ long and $0.4 \mu \mathrm{m}$ wide. A lattice structure with characteristic periodic patterns was seen in some rods, the width of a fibril was $40-70 \AA$ and they were lying parallel with the interval of $50-80 \AA$ and a transverse periodicity of $150-160 \AA$ in the longitudinal sections (fig 1). In the transverse sections, filaments of the thickness of 50-70 $\AA$ made up of squares of $60-90 \AA$ on a side.

The electron microscopic studies of the rectus femoris biopsy also revealed a remarkable increase of satellite cells (fig 2). The mean number of satellite cells per single muscle 


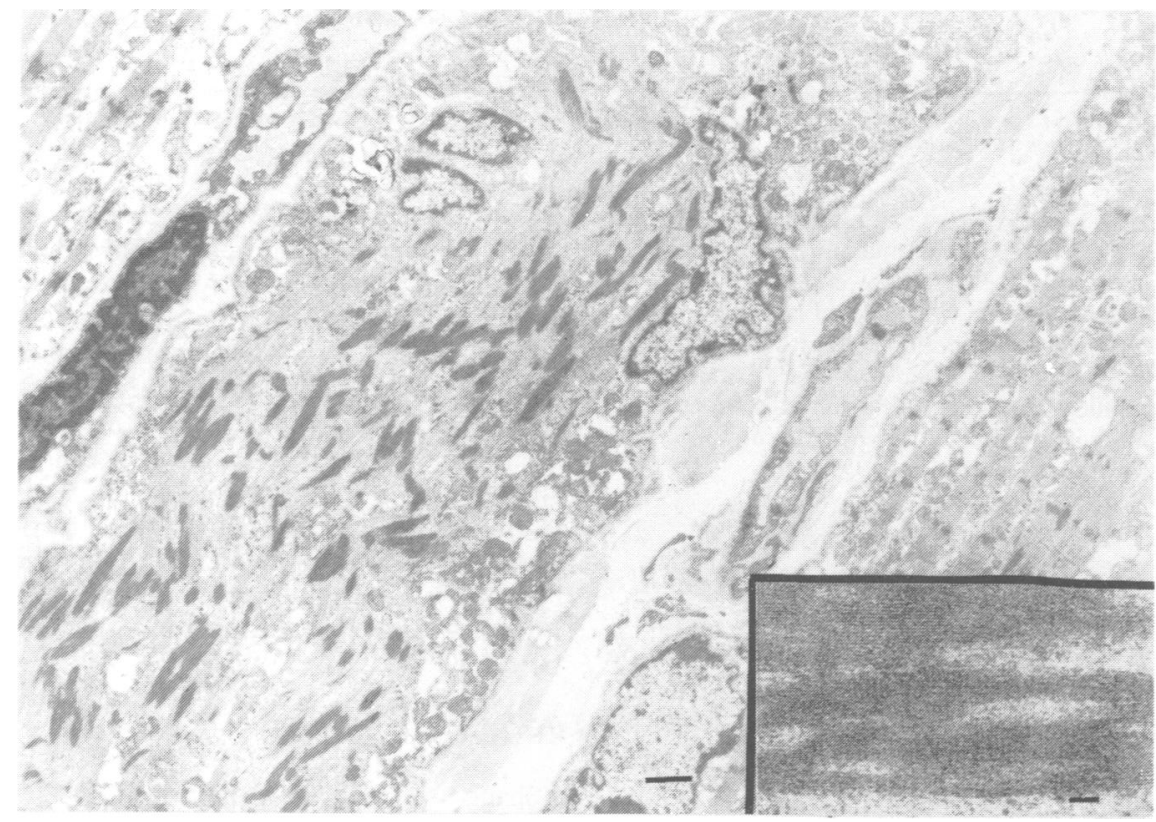

Fig 1 Longitudinal section of diaphragm. Abundant rods are seen in the fibre in the centre and other fibres contain few rods. Scale bar: $1 \mu \mathrm{m}$. Insert: high magnification of rods showing transverse and longitudinal periodicity. Scale bar: $0 \cdot 1 \mu \mathrm{m}$.

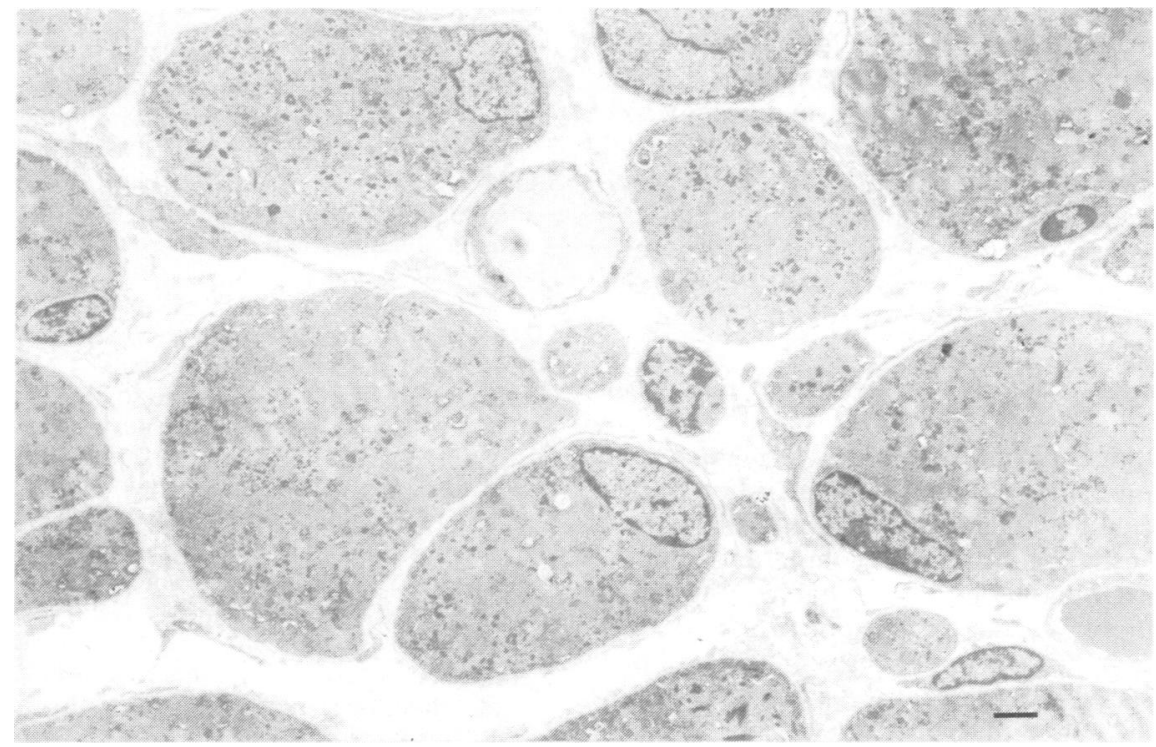

Fig 2 Cross section of biopsied rectus femoris. Most of the Z-bands appear to be irregular shaped electron-dense material. There are three satellite cells in this section. In some of them a few rough endoplasmic reticulum and polysomes are observed. Scale bar: 1 um. 
Table Number of satellite cells and satellite cell nuclei in patient and in two controls

\begin{tabular}{lclcc}
\hline & Number of satellite cells & Number of muscle fibres & Number of satellite cell nuclei & $\begin{array}{c}\text { Number of satellite cell nuclei } \\
+ \text { sarcolemmal nuclei }\end{array}$ \\
\hline Patient & 55 & $544(10 \%)$ & 36 & $164(21 \%)$ \\
Control $1 *$ & 12 & $350(3 \%)$ & 12 & $134(8 \%)$ \\
Control $2 \dagger$ & 5 & $252(2 \%)$ & 5 & $82(6 \%)$ \\
\hline
\end{tabular}

Muscle specimens used as controls were obtained from rectus femoris at autopsy in two patients (12-day-old boy* and 30-day-old girl $\dagger$ ) who died of congenital heart diseases.

fibre and the mean percentage of satellite cell nuclei (satellite cell nuclei per true sarcolemmal nuclei were determined ultrastructurally. Results were compared with two necropsy muscles of patients who died of congenital heart diseases (table). The euchromatin content did not appear to be increased and the cytoplasm was characterised by a paucity of organelles (fig 2 ). No abnormalities were present in the brain, spinal cord, and myocardium.

\section{Discussion}

The clinical features of this infant were similar to those reported in many other children with nemaline myopathy. ${ }^{4-10}$ The light and electron microscopic study of muscle in this infant revealed rod bodies in muscle fibres, especially in the diaphragm. Contrary to the reported cases, these rods were often located more in the central than in the subsarcolemmal sites, and only small number of rods showed a lattice structure.

Eight patients (five males and three females) who died of this disease in infancy have been reported, and this patient is the first case of fatal neonatal nemaline myopathy in Japan. The extent of rod formation within a muscle did not correlate with the clinical severity of the disease. However, many rods were demonstrated in the diaphragm in all five cases with fatal neonatal myopathy in which the diaphragm was examined as well as in this patient. ${ }^{1-5}$ Perhaps the fatal outcome could well be related to the presence of alterations in the diaphragm. The lattice structure of the rods was mentioned in four cases $^{145}$ and the size of the periodicity which was described in two of them ${ }^{14}$ was similar to that in this case.

The satellite cells were generally thought to play an important role in muscle regeneration. ${ }^{11}$ The number of satellite cells in the muscle in this patient was apparently greater when compared with the other patients who died of congenital heart diseases. However, the euchromatin content of satellite cell nuclei which is thought to indicate an activated protein synthesis ${ }^{12}$ did not appear to be increased in this case. In Duchenne muscular dystrophy, it is not rare to see many regenerating fibres histologically, and the activated satellite cells are significantly increased as compared to those of normal con- trols. ${ }^{13-16}$ However, the regeneration of muscle fibres in Duchenne muscular dystrophy is ineffective and they die invariably from an unknown mechanism. ${ }^{16}$ In this case only the number of satellite cells was increased and no regenerating muscle fibres were seen on light and electron microscopy. No papers reporting fatal neonatal nemaline myopathy mentioned the satellite cells in the muscle. The significance of the increased number of satellite cells in the fatal case requires further study. Finally, the presence of fatal neonatal nemaline myopathy emphasises the need for muscle biopsy in the floppy infant, so that the pathogenesis of this disease may be clarified.

\section{References}

'Shafiq SA, Dubowitz V, Peterson H de C, Milhorat AT. Nemaline myopathy. Report of a fatal case with histochemical and electron microscopic studies. Brain 1967;90:817-28.

${ }^{2}$ Kolin IS. Nemaline myopathy. A fatal case. Am J Dis Child 1967;114:95-100.

${ }^{3}$ Neustein HB. Nemaline myopathy. A family study with three autopsied cases. Arch Pathol 1973;96:192-5.

${ }^{4}$ McComb RD, Markesbery WR, O'Connor WN. Fatal neonatal nemaline myopathy with multiple congenital abnormalities. J Pediatr 1979;94:47-51.

${ }^{5}$ Gillies C, Raye J, Vasan U, Hart WE, Goldblatt PJ. Nemaline (rod) myopathy. A possible cause of rapidly fatal infantile hypotonia. Arch Pathol Lab Med 1979;103:1-5.

' Engel WK, Wanko T, Fenichel GM. Nemaline myopathy. Arch Neurol 1964;11:23-9.

7 Price HM, Gordon GB, Pearson CM, Munsat TL, Blumberg JM. New evidence for excessive accumulation of Z-band material in nemaline myopathy. Proc Natl Acad Sci USA 1965;54:1398-406.

${ }^{8}$ Gonatas NK. The fine structures of the rod-like bodies in nemaline myopathy and their relation to the Z-discs. J Neuropathol Exp Neurol 1966;25:409-20.

${ }^{9}$ Fulthorpe JJ, Gardner-Medwin D, Hudgson P, Walton JN. Nemaline myopathy. Neurology (Minneap) 1969;19:735-48.

${ }^{10}$ Karpati G, Carpenter S, Andermann F. A new concept of childhood nemaline myopathy. Arch Neurol 1971;24:291-303.

"Mauro A. Satellite cell of skeletal muscle fibers. J Biophys Biochem Cytol 1961;9:493-5.

${ }^{12}$ Frenster JH, Allfrey VG, Mirsky AE. Regressed and 
activated chromatin isolated from interphase lymphocytes. Proc Natl Acad Sci USA 1963;50:1026-32.

${ }^{13}$ Shafiq SA, Gorycki MA, Milhorat AT. An electron microscopic study of regeneration and satellite cells in human muscle. Neurology (Minneap) 1967; 17:567-74.

14 Mastaglia FL, Papadimitrior JM, Kakulas BA. Regeneration of muscle in Duchenne muscular dystrophy: An electron microscopic study. J Neurol Sci
1970;11:425-44.

15 Chou CM, Nonaka I. Satellite cells and muscle regeneration in diseased human skeletal muscles. J Neurol Sci 1977;34:131-45.

${ }^{16}$ Wakayama Y, Schotland DL, Bonilla E, Orecchio E. Quantitative ultrastructural study of muscle satellite cells in Duchenne dystrophy. Neurology (Minneap) 1979;29:401-7. 